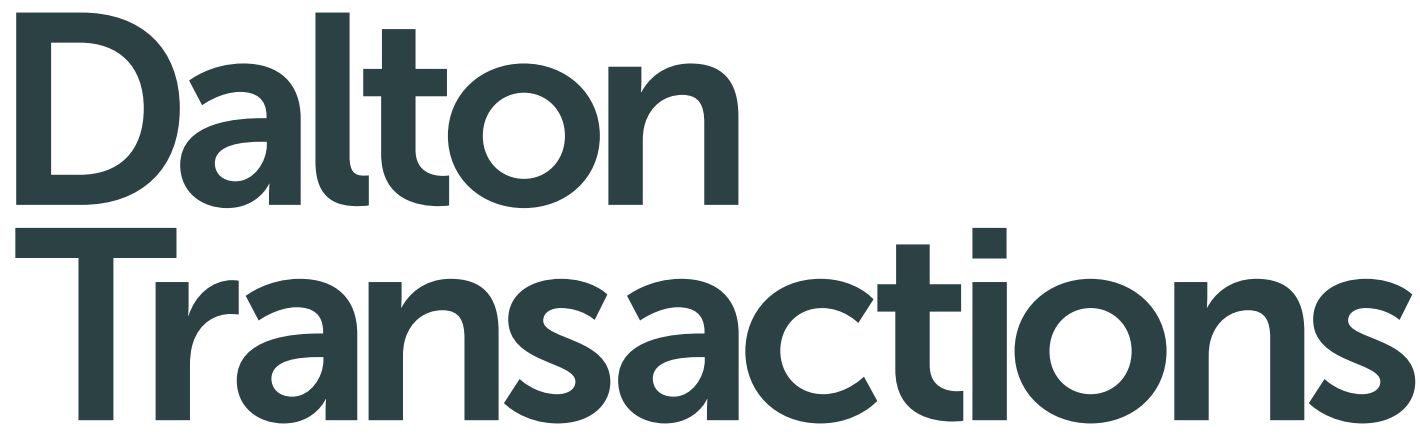

An international journal of inorganic chemistry www.rsc.org/dalton
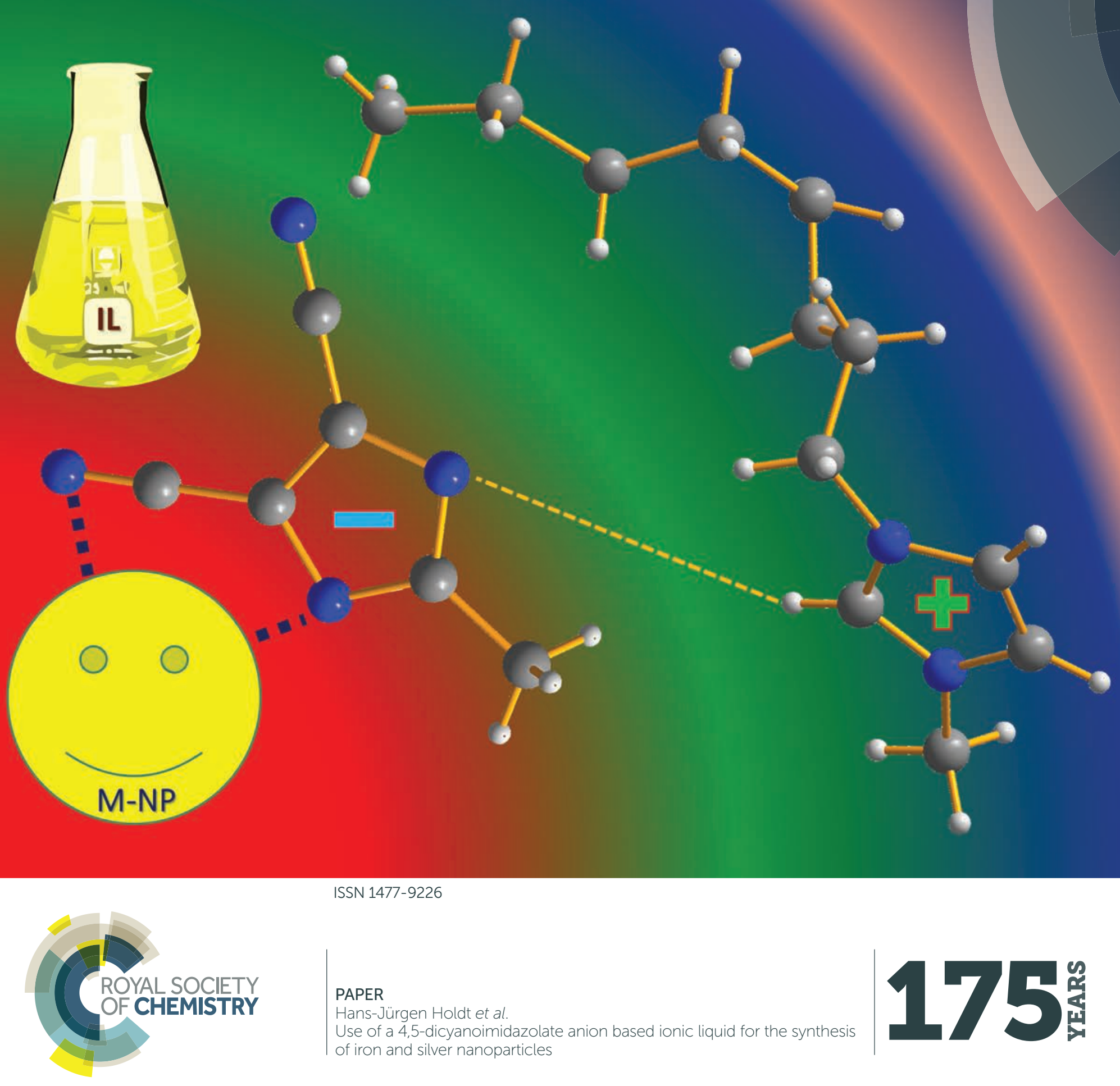


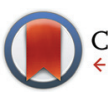

CrossMark $\leftarrow$ click for updates

Cite this: Dalton Trans., 2016, 45 5476

Received 18th January 2016, Accepted 10th February 2016

DOI: $10.1039 / \mathrm{c} 6 \mathrm{dt} 00225 \mathrm{k}$

www.rsc.org/dalton

\title{
Use of a 4,5-dicyanoimidazolate anion based ionic liquid for the synthesis of iron and silver nanoparticles $\uparrow$
}

\author{
Suvendu Sekhar Mondal, ${ }^{a}$ Dorothea Marquardt, ${ }^{\mathrm{b}}$ Christoph Janiak $^{\mathrm{b}}$ and \\ Hans-Jürgen Holdt*a
}

\begin{abstract}
Sixteen new ionic liquids (ILs) with tetraethylammonium, 1-butyl-3-methylimidazolium, 3-methyl-1octylimidazolium and tetrabutylphosphonium cations paired with 2-substituted 4,5-dicyanoimidazolate anions (substituent at C2 = methyl, trifluoromethyl, pentafluoroethyl, $N, N^{\prime}$-dimethyl amino and nitro) have been synthesized and characterized by using differential scanning calorimetry (DSC), thermogravimetric analysis (TGA). The effects of cation and anion type and structure of the resulting ILs, including several room temperature ionic liquids (RTILs), are reflected in the crystallization, melting points and thermal decomposition of the ILs. ILs exhibited large liquid and crystallization ranges and formed glasses on cooling with glass transition temperatures in the range of -22 to $-71{ }^{\circ} \mathrm{C}$. We selected one of the newly designed ILs due to its bigger size, compared to the common conventional IL anion and high electronwithdrawing nitrile group leads to an overall stabilization anion that may stabilize the metal nanoparticles. Stable and better separated iron and silver nanoparticles are obtained by the decomposition of corresponding $\mathrm{Fe}_{2}(\mathrm{CO})_{9}$ and $\mathrm{AgPF}_{6}$, respectively, under $\mathrm{N}_{2}$-atmosphere in newly designed nitrile functionalized 4,5-dicyanoimidazolate anion based IL. Very small and uniform size for Fe-nanoparticles of about $1.8 \pm$ $0.6 \mathrm{~nm}$ were achieved without any additional stabilizers or capping molecules. Comparatively bigger size of $\mathrm{Ag}$-nanoparticles was obtained through the reduction of $\mathrm{AgPF}_{6}$ by hydrogen gas. Additionally, the $\mathrm{AgPF}_{6}$ precursor was decomposed under microwave irradiation (MWI), fabricating nut-in-shell-like, that is, core-separated-from-shell Ag-nano-structures.
\end{abstract}

\section{Introduction}

Transition-metal-nanoparticles (M-NPs) are very important for technological applications in several areas of science and industry, including catalysis, chemical sensors, biocatalysts and nanomaterial technology. ${ }^{1-9}$ For example, silver (Ag)-nanoparticles (Ag-NPs) are potential building blocks for the creation of new materials with tailored properties for optical ${ }^{10}$ and medical applications. ${ }^{11-13}$ Particularly, Fe-NPs can be used for olefin hydrogenation reactions. ${ }^{14}$ Therefore, the controlled and reproducible synthesis of defined and stable M-NPs is of high importance. ${ }^{15,16}$

M-NPs can be stabilized by the ionic charge, high polarity, high dielectric constant and supramolecular network of ionic

\footnotetext{
${ }^{a}$ Insitut für Chemie, Anorganische Chemie, Universität Potsdam, Karl-LiebknechtStraße 26, 14476 Potsdam, Germany.E-mail: holdt@uni-potsdam.de ${ }^{b}$ Institut für Anorganische Chemie und Strukturchemie, Universität Düsseldorf, Universitätsstr. 1, D-40225 Düsseldorf, Germany

$\dagger$ Electronic supplementary information (ESI) available: Experimental details, elemental analysis, NMR data. See DOI: 10.1039/c6dt00225k
}

liquids (ILs). ${ }^{16-18}$ According to the DLVO (Derjaugin-LandauVerwey-Overbeek) theory, ${ }^{19}$ ILs provide an electrostatic protection in the form of a "protective shell" for M-NPs, so that no extra stabilizing molecules or reagents are needed. ${ }^{20,21}$ ILs can therefore function both as stabilizer and solvent for the preparation of small $(<5 \mathrm{~nm})$ and (generally) kinetically stabilized M-NPs. ${ }^{22,23}$ For these reasons, the chemistry of inorganic compounds and inorganic materials synthesis in ILs has attracted tremendous interest in the recent years. ${ }^{24,25}$ Interestingly, the stabilization of M-NPs in nonfunctionalized or functionalized ILs is primarily based on the IL-anions, which form the immediate layer around the nanoparticle because the molecular volume of the IL anion influences sizes and shapes of the resulting M-NPs (Fig. 1a). ${ }^{26-28}$ Experimentally $\mathrm{PF}_{6}{ }^{-}$anions from $\mathrm{BMIm}^{+} \mathrm{PF}_{6}{ }^{-}$were found on a $\mathrm{Pd}$ nanocluster surface by XPS. This supports the hypothesis that weakly coordinating anions can contribute to the stability of transition-metal nanoclusters in organic solutions or ILs. ${ }^{29}$ In addition, functional amino- ${ }^{30}$ carboxylic acid-,${ }^{31}$ hydroxyl- ${ }^{32}$ nitrile- ${ }^{33}$ or thiol- ${ }^{34}$ groups on the imidazolium cations exert an additional stabilization on M-NPs because of specific interactions of the 
a)

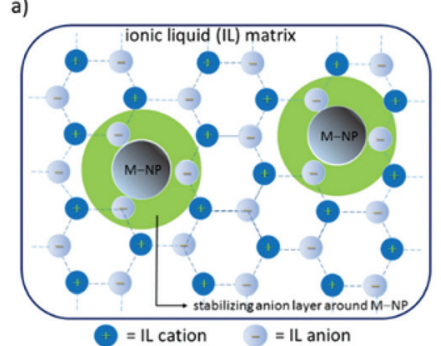

b)
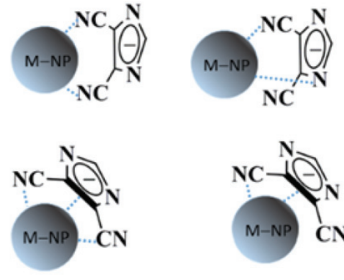

Fig. 1 (a) Schematic presentation of the stabilization of M-NPs through IL anions to prevent aggregation; ${ }^{28}$ (b) possible stabilization modes of M-NPs by nitrile functionalized IL anion.

functional group with the particle surface. The donor atom(s) of the functional group can attach to the M-NPs much like an extra stabilizing capping ligand. ${ }^{28}$ Then, the stabilization of M-NPs in functionalized-imidazolium-based ILs occurs through the cation with its functional group. Therefore, it could be a good idea to design a new types of ILs in which the IL-anion is larger in size and having functional group, showing synergistic effects for the stabilization and protection from agglomeration of M-NPs (Fig. 1b) as previously mentioned that IL anion showed weak interactions with M-NPs. ${ }^{28}$

We previously reported the synthesis and structure-thermal property of ILs based on imidazolium cations combined with 2-substituted 4,5-dicyanoimidazolate anions. ${ }^{35}$ The electron withdrawing characteristics of the nitrile functional group can be utilized to prepare correspondingly stabilized anionic imidazolate anions, which lead to opportunities for the formation of ILs containing imidazolate anions. The imidazolates have been found to not only introduce properties required for ILs, but also allow for the formation of low melting ILs, and indeed in some cases room temperature ionic liquids (RTILs). Herein, we present the synthesis and characterization of sixteen new ILs based on imidazolium, ammonium and phosphonium cations, combined with 2 -substituted 4,5-dicyanoimidazolate anions. The substituent at the C2-position of the imidazolate anion is tuned from electron-withdrawing to electron-donating groups. The effects of cation and anion type and structure on the thermal properties of the resulting ILs, including several room temperature ionic liquids (RTILs) are examined and discussed. We also show a simple synthesis method for Fe-NPs and Ag-NPs from metal precursors $\mathrm{Fe}_{2}(\mathrm{CO})_{9}$ and $\mathrm{AgPF}_{6}$, respectively, in one of the newly designed ILs. The results show that the additional nitrile functional group together with the delocalized $\pi$-electrons of the imidazolate ILanion led to a more uniform product and a better stabilization of the Fe-NPs.

\section{Results and discussion}

\subsection{IL synthesis}

Different kinds of ILs, combinations of ammonium, imidazolium and phosphonium cations and imidazolate anions, were

synthesized by metathesis reaction. In general, corresponding potassium imidazolate was combined with ammonium or imidazolium or phosphonium chloride $([\mathrm{Q}] \mathrm{Cl})$ to form a new IL in a solvent mixture of acetone/dichloromethane at room temperature (Scheme 1). ${ }^{35}$ The cations were tetraethylammonium $\left(\mathrm{Et}_{4} \mathrm{~N}^{+}\right)$, 1-butyl-3-methylimidazolium $\left(\mathrm{BMIm}^{+}\right)$, 3-methyl-1octylimidazolium $\left(\mathrm{OMIm}^{+}\right)$and tetrabutylphosphonium $\left(\mathrm{Bu}_{4} \mathrm{P}^{+}\right)$. The anions included 2-substituted 4,5-dicyanoimidazolate. Potassium 2-substituted 4,5-dicyanoimidazolate salts were prepared by the treatment of the corresponding imidazole with potassium carbonate in acetone at $20-25{ }^{\circ} \mathrm{C}$. Reaction of equimolar amounts of $[\mathrm{Q}] \mathrm{Cl}$ and the potassium 2-substituted 4,5-dicyanoimidazolate salts in acetone/dichloromethane $(1: 1$, $\mathrm{v} / \mathrm{v}$ ) at room temperature gave the corresponding [Q]imidazolate ILs with high yields after the removal of the precipitate of potassium chloride and the evaporation of the organic solvents (Scheme 1). Experimental data were supported by ${ }^{1} \mathrm{H}$ and ${ }^{13} \mathrm{C}$ NMR spectroscopy, elemental analysis and mass spectrometry (ESI†). ILs, (1-3) $\mathbf{a}^{35,36}$ and $2 \mathbf{b}^{37}$ were reported previously. All ILs were dried, prior to thermal analysis.

\subsection{Thermal characterization}

The salts or ILs varied in their physical state from highmelting solids (with tetramethylammonium cations) to ILs at room temperature, forming glassy solids on cooling. The thermal behavior of synthesized ILs was determined by thermal gravimetric analysis (TGA) and differential scanning calorimetry (DSC). The characterization data of these ILs are presented in Table 1. The influence of structural variation in the cation and anion moieties reflected their properties.

2.2.1. Thermogravimetric analyses. The thermal stability was measured by using TGA, with isocratic heating at $10{ }^{\circ} \mathrm{C}$ $\min ^{-1}$ under an air atmosphere. The decomposition temperatures are shown in Table 1. Generally, the thermal stability of the ILs is governed by the identity of the cationic and anionic core and type of side chain of the cation and anion. ${ }^{32,35}$ Herein, ILs contain the same anionic moieties; only the change of substituents at the $\mathrm{C} 2$ position at imidazolate anions and various cations can influence the decomposition of ILs (Table 1 and Fig. 2). As ILs are nonvolatile, the upper limit of the liquid range of ILs is usually given by their

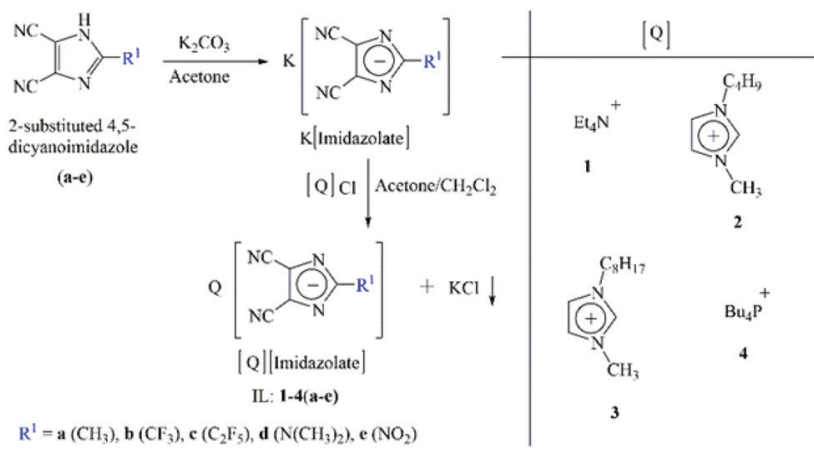

Scheme 1 Synthetic strategy of imidazolate-anion based ILs. 
Table 1 Thermal transitions for 1-4 (a-e)

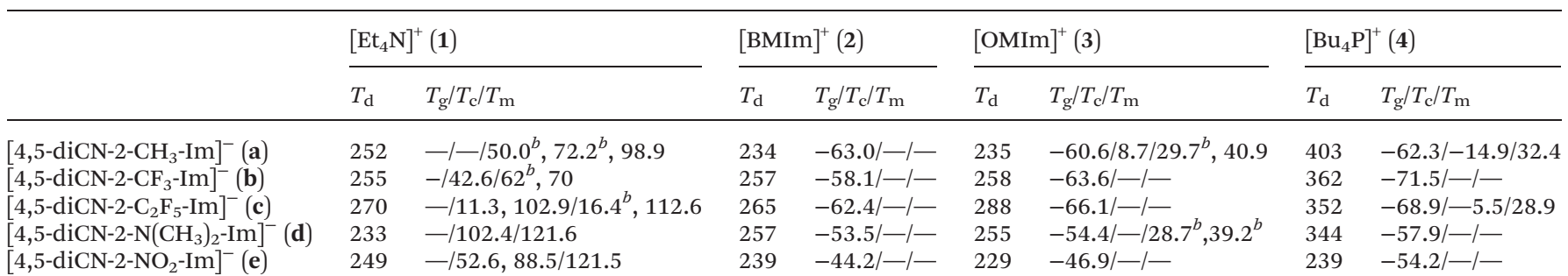

${ }^{a}$ Representative DSC traces were recorded from the transition onset temperature at a heating rate of $10{ }^{\circ} \mathrm{C}$ min ${ }^{-1}$ in the cooling/heating cycle. Decomposition temperatures were determined by TGA, heating at $10{ }^{\circ} \mathrm{C} \mathrm{min}^{-1}$. ${ }^{b}$ Solid-solid transition $\left(T_{\mathrm{s}-\mathrm{s}}\right)$. $T_{\mathrm{d}}=$ decomposition temperature, $T_{\mathrm{g}}$ $=$ glass transition temperature, $T_{\mathrm{c}}=$ crystallization temperature, $T_{\mathrm{m}}=$ melting transition temperature.

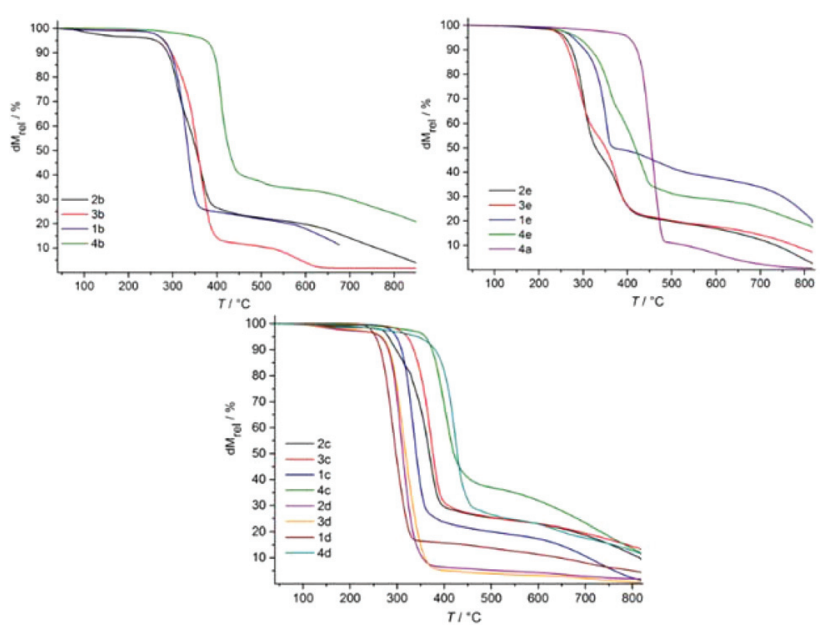

Fig. 2 Thermal decomposition of ILs.

thermal decomposition temperature, which generally lies between 233 and $403{ }^{\circ} \mathrm{C}$. 2-Substituted 4,5-dicyanoimidazolate anion-based ILs (e.g. 1c, 1d, 2b, 2d, 2e, 3b, 3d, 3e and 4a) exhibited a complete mass loss and volatilization of the component fragments occurred during heating (Fig. 2). In contrast, ILs 1e, 2c, 3c, $4 \mathbf{b}, \mathbf{4 c}, \mathbf{4 d}$ and $4 \mathbf{e}$ showed $10-15 \%$ polymeric products. Such ILs show that the decomposition occurs in two distinct steps. The first decomposition can be found at around $350{ }^{\circ} \mathrm{C}$, probably representing the cleavage of alkyl chains. A second decomposition step can be observed up to $390^{\circ} \mathrm{C}$. This leads to the assumption that first the IL reacts by the elimination of alkyl chains, maintaining the nitrogen-containing structural elements. Further, condensation of the material probably proceeds by a trimerization of nitrile groups forming triazine rings, which is a common reaction for nitriles. ${ }^{38}$ It was noted that the stabilities of the $\left[\mathrm{Bu}_{4} \mathrm{P}\right]^{+}$-based ILs (decomposition temperatures ranging from $344-403{ }^{\circ} \mathrm{C}$ ) were markedly higher than those of the other cation-based ILs. Future utilization of phosphonium salts appears promising for high temperature applications. IL $\mathbf{4 e}$ decomposed unexpectedly at low temperature probably due to the nitro group.

2.2.2. DSC analyses. DSC traces were recorded from the transition onset temperature at a heating rate of $10{ }^{\circ} \mathrm{C} \mathrm{min}-1$ in the cooling/heating cycle. The first type of behavior was observed by the ILs that showed a single glass transition $\left(T_{\mathrm{g}}\right)$ at low temperature during the cooling scan (Fig. 3a). [BMIm] $]^{+}$based ILs, $\mathbf{4 d}$ and $\mathbf{4 e}$ showed only glass transition. The second type of transition was noted with some ILs (e.g., 1c) that exhibited one solid-solid transition initially to form liquid crystalline state $\left(T_{\mathrm{m} 1}\right)$ through melting $\left(T_{\mathrm{m} 2}\right)$ at heating scan (Fig. 3b). On the cooling scan, such ILs only show the crystallization peak, exhibited a complete but inhomogeneous crystallization consisting of two distinct temperatures that were observed at cooling scan (Table 1). For example, $\mathrm{Et}_{4} \mathrm{~N}$-based ILs, one liquid crystalline state (or mesophase) also is formed. Such peak is observed before crystallization, indicating that more time was taken for orientation in liquid crystalline state as the molecular volume increased. IL 1e showed only melting transition at relatively high temperature $\left(121.5{ }^{\circ} \mathrm{C}\right)$, without showing solid-solid transition, designated as high melting salt. During cooling scan, 1e exhibited two distinct very sharp
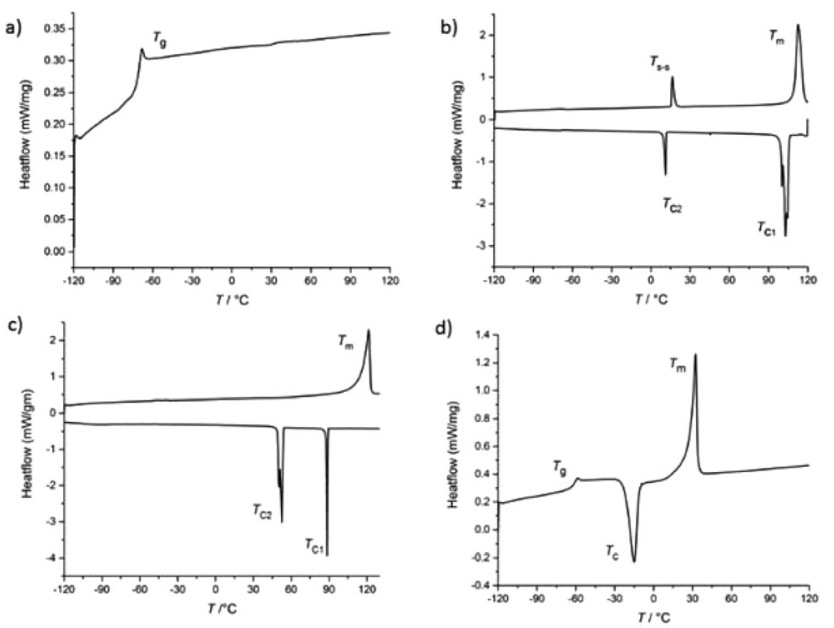

Fig. 3 DSC experiments were performed by heating the samples at a rate of $10^{\circ} \mathrm{C} \mathrm{min}^{-1}$ and temperature range -120 to $120{ }^{\circ} \mathrm{C}\left(130{ }^{\circ} \mathrm{C}\right.$ for $\left[\mathrm{Et}_{4} \mathrm{~N}\right]^{+}$based ILs). (a) IL $4 \mathrm{~b}$ shows only glass transition; (b) $1 \mathrm{c}$ exhibits a glass transition, then the soft glassy material crystallizes followed by a sudden endothermic solid-solid transition, before melting; (c) 1e IL exhibits a weakly intensified and a completely inhomogeneous crystallization and consists of two distinct temperatures, without solid-solid transition; (d) IL 4a shows clear $T_{\mathrm{g}}, T_{\mathrm{c}}$ and $T_{\mathrm{m}}$. 
crystallization points (Fig. 3c). The fourth or major type of behavior was exhibited by the remaining ILs (Fig. 3d). During the heating scan, these ILs showed a $T_{\mathrm{g}}$ at low temperature to form a supercooled liquid which transformed to an exothermic crystallization $\left(T_{\mathrm{c}}\right)$ peak at relatively high temperature, followed by a sharp melting transition $\left(T_{\mathrm{m}}\right)$ as the temperature increased further. It can be clearly seen that the liquid range for these ILs is governed principally by the choice of cation, which has the greatest influence on the lower melting (or glass) transition temperature, with the $\left[\mathrm{Bu}_{4} \mathrm{P}\right]^{+}$-based ILs $\mathbf{4}(\mathbf{a}-\mathbf{e})$ showing the lowest temperatures of all.

\subsection{M-NPs synthesis}

M-NPs can be synthesized in ILs through chemical reduction by hydrogen gas or decomposition, by means of photochemical reduction or electro-reduction/electrodeposition of metal salts where the metal atom is in a formally positive oxidation state. ${ }^{16,17,28}$ Metal carbonyls $\mathrm{M}_{x}(\mathrm{CO})_{y}$ or other $\mathrm{M}(0)$ complexes are interesting precursors for the synthesis of metal nanoparticles (M-NPs) because the metal atoms are already in their final zero-valent oxidation state. Thus, no reducing agent is necessary and the carbonyl (CO) side product is largely given off to the gas phase and thereby removed from the M-NP dispersion. Contamination from by- or decomposition products which are otherwise generated during the M-NP synthesis are therefore significantly reduced and very clean particles can thus be obtained..$^{28}$ Common to the synthesis of M-NPs in ILs is that no extra stabilizing molecules or organic solvents are needed, even if in some cases such stabilizers are added.

It has been demonstrated that stable M-NPs are obtained reproducibly by thermal or photolytic decomposition from mononuclear metal carbonyl precursors suspended in the ILs $\mathrm{BMIm}^{+} \mathrm{BF}_{4}{ }^{-}, \mathrm{BMIm}^{+} \mathrm{OTf}^{-}$and $\mathrm{BtMA}^{+} \mathrm{Tf}_{2} \mathrm{~N}^{-}\left(\mathrm{BtMA}^{+}=n\right.$-butyltrimethylammonium, $\left.\mathrm{Tf}_{2} \mathrm{~N}=\mathrm{N}\left(\mathrm{O}_{2} \mathrm{SCF}_{3}\right)_{2}, \mathrm{OTf}=\mathrm{O}_{3} \mathrm{SCF}_{3}\right)$ with a very small and uniform size of 1 to $1.5 \mathrm{~nm}$ in $\mathrm{BMIm}^{+} \mathrm{BF}_{4}{ }^{-}$ which increases with the molecular volume of the IL anion to $100 \mathrm{~nm}$ in $\mathrm{BtMA}^{+} \mathrm{Tf}_{2} \mathrm{~N}^{-}{ }^{26}$ Taubert et al. also showed that the shape, size, and aggregation behavior of gold nanoparticles depend on the IL anion. ${ }^{27}$ We have chosen one of the newly designed ILs, 3a, due to its larger size, compared to the common conventional IL anion. Its size and the high electronwithdrawing nitrile group should lead to an overall stabilization of the imidazolate anion towards M-NPs. Metal pre- cursors $\mathrm{Fe}_{2}(\mathrm{CO})_{9}$ and $\mathrm{AgPF}_{6}$ (1-2 mass \% rel. to IL, Table 2 and Scheme 2) were dispersed into dried and degassed IL, 3a and stirred for $12 \mathrm{~h}$ at RT under $\mathrm{N}_{2}$-atmosphere. The auxiliary base, $n$-butylimidazole was added to the dispersion of $\mathrm{AgPF}_{6}$ to trap the acidic $\mathrm{HPF}_{6}$ side product (Table 2, entry 3). ${ }^{39}$ The magnetic stirring bars were removed from the dispersion and the reaction mixture was subsequently heated to $210{ }^{\circ} \mathrm{C}(20 \mathrm{~W}, 6 \mathrm{~min})$ by microwave irradiation (MWI) or reduction by hydrogen gas (Table 2). The dark brown (entries 1 and 2; Table 2) and yellow (entry 3, Table 2) colored reaction products were treated under reduced pressure to eliminate volatile byproducts and M-NPs dispersions were obtained. The samples were kept under $\mathrm{N}_{2}$ atmosphere. Fig. 4a shows representative transmission electron microscopy (TEM) images of the nanoparticles obtained from the decomposition of $\mathrm{Fe}_{2}(\mathrm{CO})_{9}$ in IL 3a. Small Fe-NPs with narrow size distribution are obtained from $\mathrm{Fe}_{2}(\mathrm{CO})_{9}$ by MWI in the 4,5-dicyanoimidazolate-based IL, 3a. The sample grown in 3 a contains small and monodisperse particles with a diameter of $1.8 \pm 0.8 \mathrm{~nm}$ (103 analyzed particles, determined from TEM micrograph, Fig. 5a). The visible clustering is due to the superparamagnetic properties of Fe-NPs. Selected area electron diffraction (SAED) patterns do not show reflections indicative of a crystalline material. We therefore conclude that the particles obtained from the synthesis are amorphous Fe-NPs stabilized by the IL (Fig. 4b).

Ag-NPs were synthesized by using $\mathrm{AgPF}_{6}$ precursor in two different methods; through the reduction of hydrogen gas and MWI (Table 2). Reduction by $\mathrm{H}_{2}$ of $\mathrm{AgPF}_{6}$ in $\mathbf{3 a}$ and in the presence of $n$-butylimidazole lead to small Ag-NPs of $4 \pm 1 \mathrm{~nm}$ (Fig. 4c and 5b). From MWI we got rather large, up to several $100 \mathrm{~nm}$-sized silver particles. Interestingly, core-shell Ag

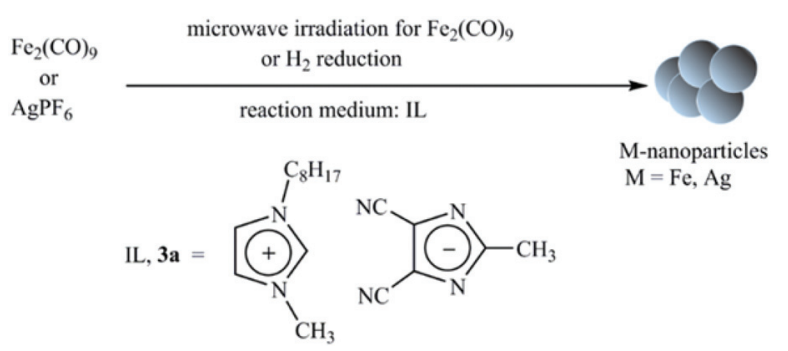

Scheme 2 Formation of Fe-and Ag-NPs by microwave irradiationinduced decomposition or $\mathrm{H}_{2}$ reduction under $\mathrm{N}_{2}$ atmosphere in IL.

Table 2 Fe-/Ag-NPs synthesized by microwave irradiation-induced decomposition and $\mathrm{H}_{2}$ reduction of $\mathrm{Fe}_{2}(\mathrm{CO})_{9}$ and $\mathrm{AgPF}_{6}$, respectively

\begin{tabular}{lllllll}
\hline Entry & $\mathrm{IL}, \mathbf{3 a}[\mathrm{g}]$ & Precursor & Amount $[\mathrm{g}]$ & Decomposition method & Mass \% of metal rel. to IL & $\varnothing \pm \sigma^{a}[\mathrm{~nm}] \pm[\mathrm{nm}]^{a}$ \\
\hline 1 & 1.04 & $\mathrm{Fe}_{2}(\mathrm{CO})_{9}$ & 0.0338 & $\mathrm{MWI}^{b}$ & 1 & $1.8 \pm 0.6^{c}$ \\
2 & 0.34 & $\mathrm{AgPF}_{6}$ & 0.0078 & $\mathrm{MWI}^{b}$ & 1 & Core-shell nano-structures $^{f}$ \\
3 & 0.70 & $\mathrm{AgPF}_{6}$ & 0.0330 & $\mathrm{H}_{2}{ }^{b, e}$ & 2 & $4.0 \pm 1.0^{g}$
\end{tabular}

${ }^{a}$ Particle diameter \pm standard deviation. ${ }^{b}$ Microwave (MWI) conditions ( $20 \mathrm{~W}$, run time: $30 \mathrm{~s}$, hold time: 6 min; $210{ }^{\circ} \mathrm{C}$ ). ${ }^{c} 103$ analyzed particles, determined from TEM micrographs, after four months form synthesis. ${ }^{d}$ Hydrogen reduction $\left(\mathrm{H}_{2}, 4\right.$ bar, $100{ }^{\circ} \mathrm{C}$ oil-bath temperature, $\left.1 \mathrm{~h}\right)$. ${ }^{e} n$-Butylimidazole added. ${ }^{f}$ HRTEM and HAADF-STEM micrographs, no statistics of particle diameters was obtained, measured after three month later from the synthesis. ${ }^{g}$ HAADF-STEM micrographs, 65 particles measured; sample age six months, prepared in the presence of $n$-butylimidazole as auxiliary base to remove the $\mathrm{HPF}_{6}$ by-product. ${ }^{39}$ 


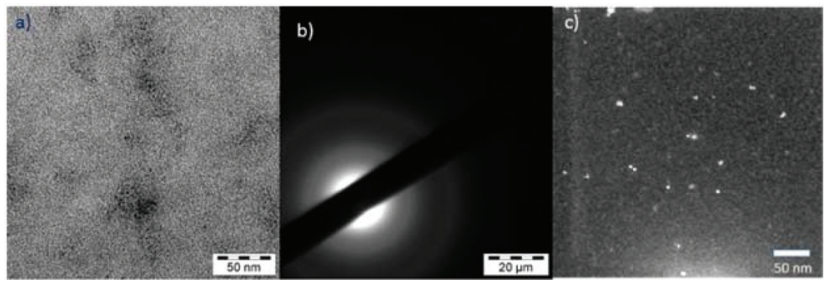

Fig. 4 (a) TEM-image of Fe-NPs in $3 a$ six weeks after synthesis (see Fig. $\mathrm{S} 1$ in $\mathrm{ESI} \dagger$ for enlarged version and additional images); (b) SAED-image of Fe-NP (the black bar in the SAED is the beam stopper) indicating amorphous material (no well-defined sharp reflections); (c) HAADF-STEM image of Ag-NPs after six weeks after synthesis in $3 a$, by $\mathrm{H}_{2}$ gas reduction.
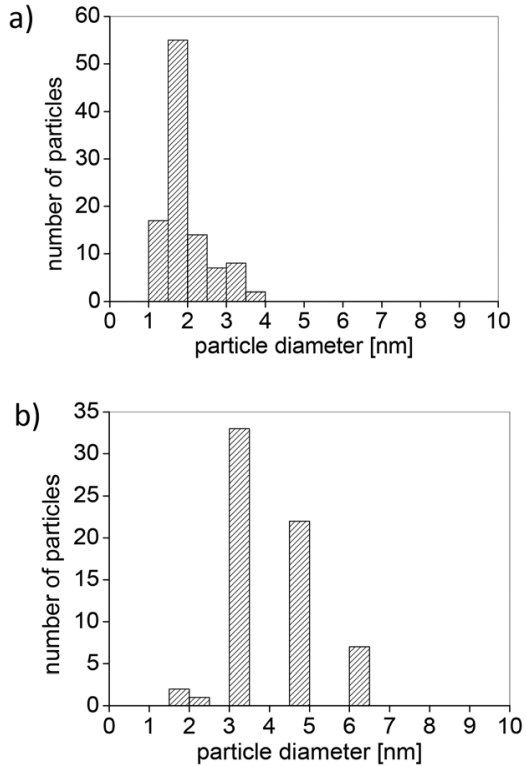

Fig. 5 (a) Histogram of Fe-NP diameter distribution $(1.8 \pm 0.8 \mathrm{~nm}$, based on 103 particles); (b) histogram of Ag-NP diameter distribution (4. $\pm 1.0 \mathrm{~nm}$, based on 65 particles).
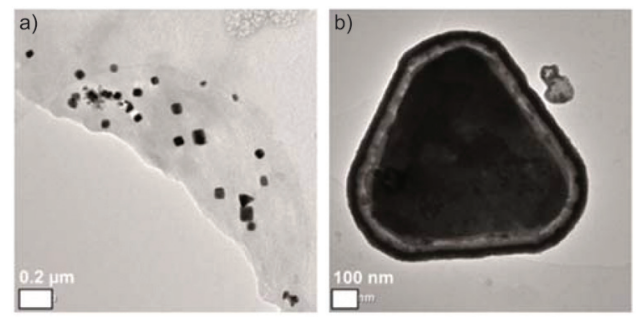

Fig. 6 HRTEM-images of Ag core-shell nanostructures obtained in 3a by microwave decomposition of $\mathrm{AgPF}_{6} ;$ (a) overview of the large, facetted Ag-NPs; (b) close-up image of a core-shell nanostructure.

nanostructures (Fig. 6 and 7) were formed by decomposing the $\mathrm{AgPF}_{6}$ precursor under MWI, proven by energy dispersive X-ray spectroscopy (EDX). In the high-angle annular dark field scanning transmission electron microscopy (HAADF-STEM)
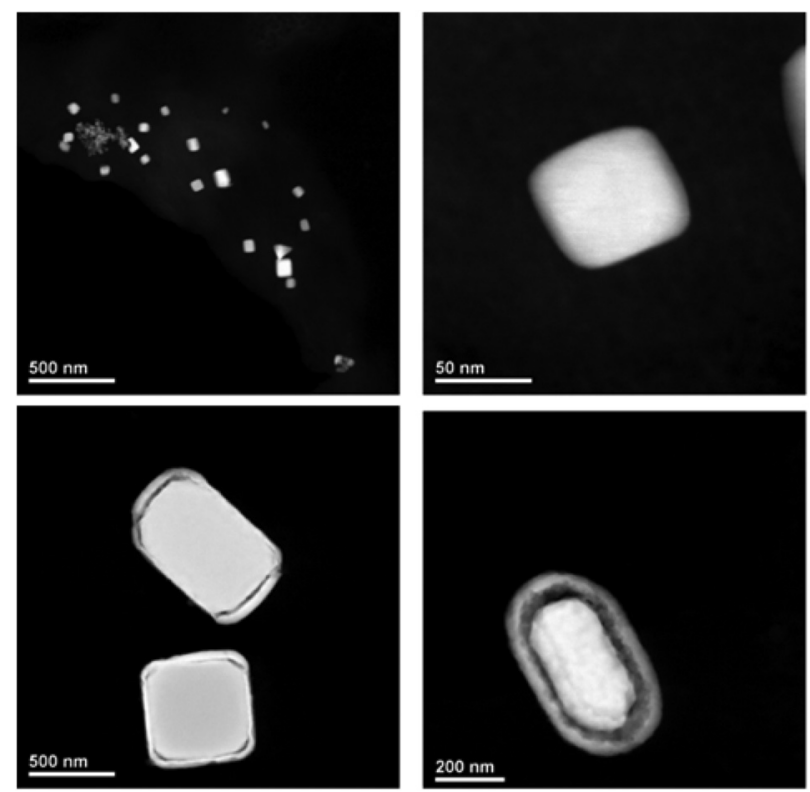

Fig. 7 HAADF-STEM images of Ag-NPs and Ag core-shell nanostructures, prepared in $3 a$ through microwave irradiation-induced decomposition of $\mathrm{AgPF}_{6}$.

mode, the nanoparticles are shown bright against a dark background. The STEM images revealed free space between the core and the shell of the Ag nanostructures, similar to a nut in its shell. Hence, the Ag-nanostructure can be termed nut-inshell-like, that is, core-separated-from-shell. The elemental analysis of the shell and the core of Ag-nanostructure displayed high peaks only for $\mathrm{Ag}$ (besides small $\mathrm{Cu}$ peaks for the sample holder, Fig. 8). At the moment we can only speculate on the origin of this apparently unprecedented phenomenon. We suggest that during sample preparation or under the action of the electron beam in the TEM small silver clusters agglomerate around the larger micrometer-sized structures. As the larger structures have a surface layer of IL cations and anions the small clusters cannot integrate into the large particle but can only form a disconnected layer around it.

\section{Materials and methods}

Tetraethylammonium chloride, 1-butyl-3-methylimidazolium chloride, 3-methyl-1-octylimidazolium chloride, tetrabutylphosphonium chloride, $\mathrm{Fe}_{2}(\mathrm{CO})_{9}, \mathrm{AgPF}_{6}$ and solvents were used as purchased from commercial suppliers (Sigma-Aldrich, Fluka, Alfa Aesar, IoLiTec and others) without further purification, if not stated otherwise. 2-Substituted 4,5-dicyanoimidazoles $\left(\mathrm{R}^{1}=\right.$ $\mathrm{CF}_{3}, \mathrm{C}_{2} \mathrm{~F}_{5}, \mathrm{~N}\left(\mathrm{CH}_{3}\right)_{2}$ and $\left.\mathrm{NO}_{2}\right)$ were synthesized according to published procedures. ${ }^{40,41} \mathrm{ILs}, \mathbf{1} \mathbf{b}$ and $\mathbf{1 c}$ are prepared according to the published procedure (see ESI $\dagger$ for details). ${ }^{35}$

\subsection{Nanoparticles synthesis}

Microwave vials with a Teflon septum were used. They were charged with IL, $3 \mathbf{a}$ and $\mathrm{Fe}_{2}(\mathrm{CO})_{9}$ or $\mathrm{AgPF}_{6}$ by placing the vial 


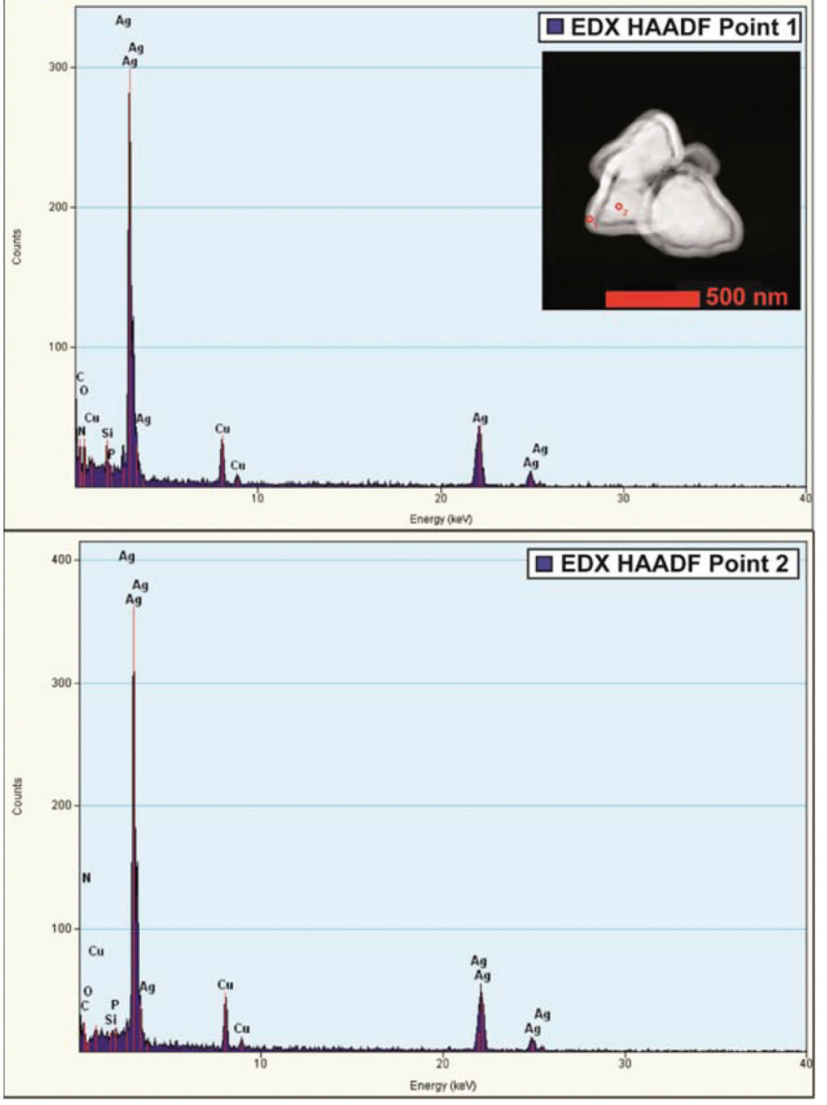

Fig. 8 EDX (HAADF)-spectra of core (point 1) (top) and shell (point 2) (bottom) of core-shell Ag nano-structure in HAADF-STEM, showing the presence of $\mathrm{Ag}$ (at the HAADF-STEM image inset of the nanostructure).

in a Schlenk tube or by handling in a glovebox. The general procedure for preparing of 1-2 wt\% M-NPs dispersion in 3a was to add the required mass of metal precursor under nitrogen to the dried and degassed IL (0.34-1.04 g). A 1-2 wt\% dispersion of M-NPs in 3a was prepared by adding the required mass of metal salt $\left[\mathrm{Fe}_{2}(\mathrm{CO})_{9}: 0.0338 \mathrm{~g} ; 0.098 \mathrm{mmol}\right.$ at entry 1, $\mathrm{AgPF}_{6}: 0.0078 \mathrm{~g} ; 0.031 \mathrm{mmol}$ at entry 2 and $\mathrm{AgPF}_{6}: 0.0330 \mathrm{~g}$; $0.13 \mathrm{mmol}$ at entry 3] under nitrogen to the dried and degassed IL. The metal salts were finely dispersed in the IL by stirring for $12 \mathrm{~h}$ at room temperature under nitrogen. For entry $3 n$-butylimidazole (2.0 equiv., $0.032 \mathrm{~g}, 34 \mu \mathrm{L}$ ) was added as auxiliary base to trap the $\mathrm{HPF}_{6}$ side product. The magnetic stirring bar was removed from the dispersion and the reaction mixture was subsequently heated to $210{ }^{\circ} \mathrm{C}(20 \mathrm{~W}, 6 \mathrm{~min})$ by microwave irradiation (MWI, CEM Discover). The dark brown (entries 1 and 2; Table 2) and yellow (entry 3, Table 2) colored M-NPs dispersions were obtained. They were degassed under reduced pressure for $30 \mathrm{~min}$ to remove $\mathrm{CO}$ and other by-products.

\subsection{Characterization}

Melting point, crystallization and glass transition temperatures of the ILs were determined by differential scanning calorimetry using Mettler-Toledo DSC1 Stare System. Data were col- lected under a flow of nitrogen, using an average sample weight of 5-8 $\mathrm{mg}$ placed in an aluminum pan sealed by using pin-hole caps. Experiments were performed by heating the samples at a rate of $10{ }^{\circ} \mathrm{C} \mathrm{min}^{-1}$. The DSC instrument was adjusted so that zero heat flow was between 0 and $-0.5 \mathrm{~mW}$ and the baseline drift was less than $0.1 \mathrm{~mW}$ over the temperature range -120 to $120^{\circ} \mathrm{C}\left(130{ }^{\circ} \mathrm{C}\right.$ for $\left[\mathrm{Et}_{4} \mathrm{~N}\right]^{+}$based ILs). The transition temperatures were determined as inflection points using Mettler Toledo STARe software V9.30. An empty sample pan was considered as reference. TEM images were taken at room temperature on a Zeiss LEO 912 TEM operating at an accelerating voltage of $120 \mathrm{kV}$. HR-TEM and HAADF-STEM images were obtained on a FEI TECNAI G ${ }^{2}$ F 20 (S)TEM (operating at $200 \mathrm{kV}$ ), TITAN 80-300 image CS-corrected, TITAN 80-300 probe CS-corrected STEM and TITAN $^{3} 60-300$ (all operating at $300 \mathrm{kV}$ ). Samples were deposited on $200 \mathrm{~mm}$ carbon-coated copper grids.

\section{Conclusions}

ILs make a unique architectural platform where the properties of cation and anion could be independently modified to design new functionalized ILs with low melting points and the effect of structural modification reflects the properties of ILs. The investigations of potential ILs containing planar heterocyclic anions and their structure-property relationship have been largely neglected. We have reported the synthesis and characterization of new ILs based on 2-substituted 4,5-dicyanoimidazolate anions combined with various cations and the resultant ILs reflected the thermal transition behavior.

The main finding of the current work is that one of the nitrile functionalized imidazolate anion based IL can also be efficient reaction media and stabilizers of M-NPs if used as pure phases and not in aqueous solution. In particular the imidazolate anion appears to lead to a well-controlled nucleation and growth process, which is illustrated by the narrow size distribution of the resulting Fe-NPs. Moreover, the nitrile functionality of IL anion stabilizes the particles over extended periods of time, which (i) is an indication of a rather strong interaction of the IL with the Fe-NPs and (ii) could be useful for practical applications, such as functional fluids and catalyst. Additionally, large core-shell Ag nano-structures and small Ag-NPs were fabricated when $\mathrm{AgPF}_{6}$ precursor was decomposed under microwave irradiation and through the reduction by $\mathrm{H}_{2}$ gas, respectively. The previously reported additional stabilization of M-NPs using task-specific ILs were the changing the functionalities at IL cation. To the best of our knowledge, for the first time we used nitrile functionalized imidazolate anion base IL as a task-specific IL for the synthesis of M-NPs. Nevertheless, the current result shows that the interaction between an IL anion and its functional group for the stabilization of (growing) nanocrystal is far from understood, but that a detailed understanding of the IL-inorganic interaction, the thermodynamics and kinetics, and the nucleation process in particular is necessary for a true rational design of M-NPs from task-specific ILs. 


\section{Acknowledgements}

Authors gratefully thank Mr Karsten Behrens and Sabastian Bake (Intsitut für Chemie, Universität Potsdam) for TGA and DSC measurements, respectively, Dr Juri Barthel and the Ernst Ruska-Centre (ER-C) for Microscopy and Spectroscopy with Electrons, Jülich Research Centre and RWTH Aachen University, 52425 Jülich (Germany) for help and access to the HR-TEM facilities. This work was financially supported by Universität Potsdam and DFG grant Ja466/31-1 within priority program SPP 1708.

\section{References}

1 S. H. Yu, L. R. MacGillivray and C. Janiak, CrystEngComm, 2012, 14, 7531-7534.

2 R. Marcos Esteban, H. Meyer, J. Kim, C. Gemel, R. A. Fischer and C. Janiak, Eur. J. Inorg. Chem., 2015, DOI: 10.1002/ejic.201500969; R. Marcos Esteban, K. Schütte, D. Marquardt, J. Barthel, F. Beckert, R. Mülhaupt and C. Janiak, Nano-Structures \& NanoObjects, 2015, 2, 28-34.

3 C. N. R. Rao, H. S. S. Ramakrishna Matte, R. Voggu and A. Govindaraj, Dalton Trans., 2012, 41, 5089-5120.

4 M. Kim, V. N. Phan and K. Lee, CrystEngComm, 2012, 14, 7535-7548.

5 J. Hu, Q. Yang, L. Yang, Z. Zhang, B. Su, Z. Bao, Q. Ren, H. Xing and S. Dai, ACS Catal., 2015, 5, 6724-6731.

6 Y. Hatakeyama, K. Judai, K. Onishi, S. Takahashi, S. Kimura and K. Nishikawa, Phys. Chem. Chem. Phys., 2016, DOI: 10.1039/C5CP04123F.

7 A. El Kadib, P. Hesemann, K. Molvinger, J. Brandner, C. Biolley, P. Gaveau, J. J. Moreau and D. Brunel, J. Am. Chem. Soc., 2009, 131, 2882-2892.

8 C. Janiak, Metal Nanoparticle Synthesis in Ionic Liquids, in Catalysis in Ionic Liquids: From Catalyst Synthesis to Application, ed. C. Hardacre and V. Parvulescu, RSC Publishing, Cambridge, 2014, ch. 11, p. 537-577.

9 K. S. Lee and M. A. El-Sayed, J. Phys. Chem. B, 2006, 110, 19220-19225; P. Lloret, G. Ybarra, P. Granell, L. Socolovsky and C. Moina, Nano-Structures \& Nano-Objects, 2015, 4, 9-14.

10 L. Kvitek, M. Vanickova, A. Panacek, J. Soukupova, M. Dittrich, E. Valentova, R. Prucek, M. Bancirova, D. Milde and R. Zboril, J. Phys. Chem. C, 2009, 113, 42964300; M. Alloisio, S. Zappia, A. Demartini, M. I. Martinez Espinoza, M. Ottonelli, G. Dellepiane, S. Thea, O. Cavalleri and R. Rolandi, Nano-Structures \& Nano-Objects, 2015, 4, 15-22.

11 P. Graf, A. Mantion, A. Foelske, A. Shkilnyy, A. Masic, A. F. Thünemann and A. Taubert, Chem. - Eur. J., 2009, 15, 5831-5844.

12 A. Mantion, A. G. Guex, A. Foelske, L. Mirolo, K. M. Fromm, M. Painsi and A. Taubert, Soft Matter, 2008, 4, 606-617.
13 A. Mantion, P. Graf, I. Florea, A. Haase, A. F. Thünemann, A. Mašić, O. Ersen, P. Rabu, W. Meier, A. Luch and A. Taubert, Nanoscale, 2011, 3, 5168-5179.

14 V. Kelsen, B. Wendt, S. Werkmeister, K. Junge, M. Beller and B. Chaudret, Chem. Commun., 2013, 49, 3416-3418.

15 D. König, K. Richter, A. Siegel, A. V. Mudring and A. Ludwig, Adv. Funct. Mater., 2014, 24, 2049-2056.

16 J. Dupont and J. D. Scholten, Chem. Soc. Rev., 2010, 39, 1780-1804.

17 K. Richter, P. S. Campbell, T. Baecker, A. Schimitzek, D. Yaprak and A. V. Mudring, Phys. Status Solidi B, 2013, 250, 1152-1164.

18 M. A. Neouze, J. Mater. Chem., 2010, 20, 9593-9607.

19 E. J. W. Verwey and J. T. G. Overbeek, Theory of the Stability of Lyophobic Colloids, Dover Publications, Mineola, New York, 2nd edn, 1999.

20 M. Antonietti, D. Kuang, B. Smarly and Y. Zhou, Angew. Chem., Int. Ed., 2004, 43, 4988-4992.

21 H. Kaper, F. Endres, I. Djerdj, M. Antonietti, B. M. Smarsly, J. Maier and Y. S. Hu, Small, 2007, 3, 1753-1763.

22 E. Redel, M. Walter, R. Thomann, C. Vollmer, L. Hussein, H. Scherer, M. Krüger and C. Janiak, Chem. - Eur. J., 2009, 15, 10047-10059.

23 K. Richter, A. Birkner and A. V. Mudring, Phys. Chem. Chem. Phys., 2011, 13, 7136-7141.

24 E. Redel, J. Krämer, R. Thomann and C. Janiak, J. Organomet. Chem., 2009, 694, 1069-1075; J. Krämer, E. Redel, R. Thomann and C. Janiak, Organometallics, 2008, 27, 1976-1978.

25 R. Marcos Esteban, K. Schütte, P. Brandt, D. Marquardt, H. Meyer, F. Beckert, R. Mülhaupt, H. Kölling and C. Janiak, Nano-Structures \& Nano-Objects, 2015, 2, 11-18; K. Klauke, B. Hahn, K. Schütte, J. Barthel and C. Janiak, Nano-Structures \& Nano-Objects, 2015, 1, 24-31; K. Schütte, A. Doddi, C. Kroll, H. Meyer, C. Wiktor, C. Gemel, G. van Tendeloo, R. A. Fischer and C. Janiak, Nanoscale, 2014, 6, 5532-5554; K. Schütte, H. Meyer, C. Gemel, J. Barthel, R. A. Fischer and C. Janiak, Nanoscale, 2014, 6, 3116-3126.

26 E. Redel, R. Thomann and C. Janiak, Chem. Commun., 2008, 1789-1791.

27 V. Khare, Z. Li, A. Mantion, A. A. Ayi, S. Sonkaria, A. Voelkl, A. F. Thünemann and A. Taubert, J. Mater. Chem., 2010, 20, 1332-1339.

28 C. Janiak, Z. Naturforsch., 2013, 68b, 1059-1089.

29 A. P. Umpierre, G. Machado, G. H. Fechner, J. Morais and J. Dupont, Adv. Synth. Catal., 2005, 347, 1404-1412.

30 R. Marcilla, D. Mecerreye, I. Odrizola, J. A. Pomposo, J. Rodriguez and I. Mondragon, Nano, 2007, 2, 169-173.

31 D. Marquardt, Z. Xie, A. Taubert, R. Thomann and C. Janiak, Dalton Trans., 2011, 40, 8290-8293.

32 L. C. Branco, N. J. Rosa, J. J. Moura Ramos and C. A. M. Alfons, Chem. - Eur. J., 2002, 8, 3671-3677.

33 D. Zhao, Z. Fei, T. J. Geldbach, R. Scopeliti and P. Dyson, J. Am. Chem. Soc., 2004, 126, 15876-15882.

34 H. Itoh, K. Naka and Y. Chujo, J. Am. Chem. Soc., 2004, 126, 3026-3027. 
35 S. S. Mondal, H. Müller, M. Junginger, A. Kelling, U. Schilde, V. Strehmel and H.-J. Holdt, Chem. - Eur. J., 2014, 20, 8170-8181.

36 S. S. Mondal, A. Bhunia, S. Demeshko, A. Kelling, U. Schilde, C. Janiak and H.-J. Holdt, CrystEngComm, 2014, 16, 39-42.

37 L. Niedzicki, E. Karpierz, M. Zawadzki, M. Dranka, M. Kasprzyk, A. Zalewska, M. Marcinek, J. Zachara, U. Domańska and W. Wieczorek, Phys. Chem. Chem. Phys., 2014, 16, 11417-11425.
38 J. P. Paraknowitsch, J. Zhang, D. Su, A. Thomas and M. Antonetti, Adv. Mater., 2010, 22, 87-92.

39 E. Redel, R. Thomann and C. Janiak, Inorg. Chem., 2008, 47, 14-16.

40 L. Niedzicki, G. Z. Zukowska, M. Bukowska, P. Szczeciński, S. Grugeon, S. Laruelle, M. Armand, S. Panero, B. Scrosati, M. Marcinek and W. Wieczorek, Electrochim. Acta, 2010, 55, 1450-1454.

41 Y. Lu and G. Just, Tetrahedron, 2001, 57, 1677-1687. 